\title{
A Case of Malignant Lymphoma With Diastolic Heart Failure
}

\author{
Haruhiro Toko, MD; Fumio Terasaki, MD; Yoshihide Kawakami, MD; Tetsuya Hayashi, MD; \\ Michihiro Suwa, MD; Yuzo Hirota, MD; Yasushi Kitaura, MD; Keishiro Kawamura, MD; \\ Toshiyuki Takesako, MD**; Tamaki Maeda, MD*; Hiroshi Mori, MD*
}

In patients with malignant lymphoma, the first signs and symptoms are frequently noncardiac and clinical manifestations of cardiac involvement are often nonspecific. This case report presents a patient with malignant lymphoma whose first manifestation was characteristic of heart failure, mainly due to diastolic dysfunction, and whose postmortem examination revealed massive myocardial invasion. (Jpn Circ J 1998; 62: 863-867)

Key Words: Cardiac involvement; Diastolic heart failure; Malignant lymphoma

$\mathbf{O}$ $\mathrm{f}$ the patients dying from malignant lymphoma $8-25 \%$ are found to have cardiac involvement at autopsy ${ }^{1-4}$ But in most cases the cardiac involvement is not detected before death, because the clinical manifestations of the cardiac involvement are often nonspecific and the first symptoms and signs are frequently noncardiac. We present a patient with malignant lymphoma, whose first manifestation was characteristic of heart failure, mainly due to diastolic dysfunction, and whose postmortem examination revealed massive myocardial invasions.

\section{Case Report}

A 49-year-old Japanese woman was admitted to hospital with a history of dyspnea and chest oppression. She was totally healthy until the middle of December 1996, when she noted dyspnea on exertion. She consulted a nearby doctor on January 3, 1997, where an electrocardiogram (ECG) showed inverted T waves in I, II, III, aVF and V3-6. An echocardiogram showed symmetrical left ventricular hypertrophy and the peripheral blood examination revealed $1.0 \%$ atypical lymphocytes and $1.0 \%$ meta-myelocytes. She was referred to Osaka Medical College Hospital on January 9, 1997 for further examination.

On physical examination, she was $150 \mathrm{~cm}$ in height, 53 $\mathrm{kg}$ in weight, pulse rate was 110 beats $/ \mathrm{min}$ and regular, and blood pressure was $106 / 80 \mathrm{mmHg}$. Skin eruptions on the anterior chest and back were noted. Heart sounds were normal and no murmur was audible. Liver, spleen, kidney and lymph nodes were not palpable.

Initial laboratory tests yielded the following (Table 1): white blood cell count of $3400 \mu 1$ (with $1.5 \%$ myelocytes, $0.5 \%$ meta-myelocytes, $1.5 \%$ atypical lymphocytes), red blood cell count of $3.97 \times 10^{6} \mu 1$, hemoglobin of $11.7 \mathrm{~g} / \mathrm{dl}$, hematocrit of $36.8 \%$, platelet count of $18.1 \times 10^{4} \mu 1$, aspar-

(Received April 10, 1998; revised manuscript received July 14, 1998; accepted July 17, 1998)

Third Department of Internal Medicine and *Second Department of Pathology, Osaka Medical College and **Department of Internal Medicine, Midorigaoka Hospital, Takatsuki, Japan

Mailing address: Fumio Terasaki, MD, The Third Division, Department of Internal Medicine, Osaka Medical College, 2-7 Daigakumachi, Takatsuki 569-8686, Japan tate aminotransferase (GOT) of $64 \mathrm{IU} / \mathrm{L}$, alanine aminotransferase (GPT) of $55 \mathrm{IU} / \mathrm{L}$, lactate dehydydrogenase $(\mathrm{LDH})$ of $1317 \mathrm{IU} / \mathrm{L}$, creatine kinase $(\mathrm{CK})$ of $82 \mathrm{IU} / \mathrm{L}$, blood urea nitrogen (BUN) of $12 \mathrm{mg} / \mathrm{dl}$, creatinine of 0.6 $\mathrm{mg} / \mathrm{dl}$, uric acid of $12.2 \mathrm{mg} / \mathrm{dl}$ and C-reaactive protein (CRP) of $5.55 \mathrm{mg} / \mathrm{dl}$. In summary, from the elevation of LDH with a relative increase in isozymes 2 and 3, associated with the elevation of uric acid, a hematic malignant disease could not be ruled out. No apparent anemia was observed.

The ECG showed sinus tachycardia ( 110 beats/min) and inverted $\mathrm{T}$ waves in I, II, III, aVF and V3-6 (Fig 1). The chest radiograph on admission demonstrated cardiomegaly

Table 1 Initial Laboratory Studies

\begin{tabular}{|c|c|}
\hline \multicolumn{2}{|l|}{ Peripheral Blood } \\
\hline Red blood cells & $3.97 \times 10^{6}$ a $l$ \\
\hline Hemoglobin & $11.7 \mathrm{~g} / \mathrm{dl}$ \\
\hline Hematocrit & $36.8 \%$ \\
\hline Platelets & $18.1 \times 10^{4} \mu l$ \\
\hline White blood cells & 3,400 a $l$ \\
\hline Myelocytes & $1.5 \%$ \\
\hline Meta-myelocytes & $0.5 \%$ \\
\hline Atypical lymphocytes & $1.5 \%$ \\
\hline \multicolumn{2}{|l|}{ Bone Marrow } \\
\hline Megakaryocytes & $0.4 \%$ \\
\hline Erythroblasts & $14.6 \%$ \\
\hline Leukocytes & $79.7 \%$ \\
\hline Atypical lymphocytes & $0.1 \%$ \\
\hline \multicolumn{2}{|l|}{ Blood chemistry } \\
\hline$G O T$ & $64 I U / L$ \\
\hline$G P T$ & $55 \mathrm{IU} / \mathrm{L}$ \\
\hline$L D H$ & 1,317IU/L \\
\hline isozym 1 & $10 \%$ \\
\hline 2 & $44 \%$ \\
\hline 3 & $35 \%$ \\
\hline 4 & $9 \%$ \\
\hline 5 & $2 \%$ \\
\hline$C K$ & $82 \mathrm{IU} / \mathrm{L}$ \\
\hline$B U N$ & $12 \mathrm{mg} / \mathrm{dl}$ \\
\hline Creatinine & $0.6 \mathrm{mg} / \mathrm{dl}$ \\
\hline Uric acid & $12.2 \mathrm{mg} / \mathrm{dl}$ \\
\hline$C R P$ & $5.55 \mathrm{mg} / \mathrm{dl}$ \\
\hline Adrenomedullin & $58.19 \mathrm{fmol} / \mathrm{ml}$ \\
\hline
\end{tabular}



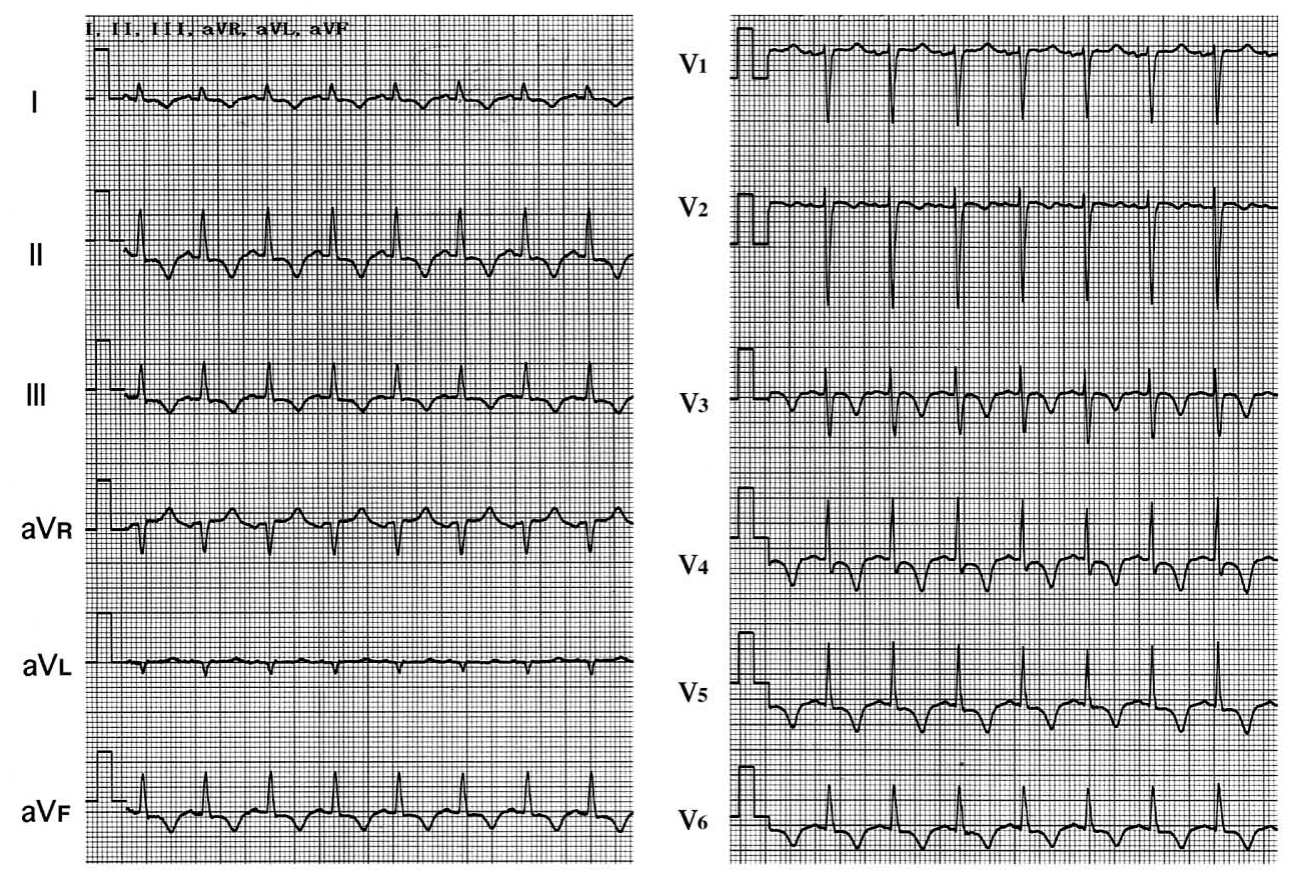

Fig 1. Electrocardiogram on admission. Inverted $\mathrm{T}$ waves were observed in I, II, III, a VF and V3-6.

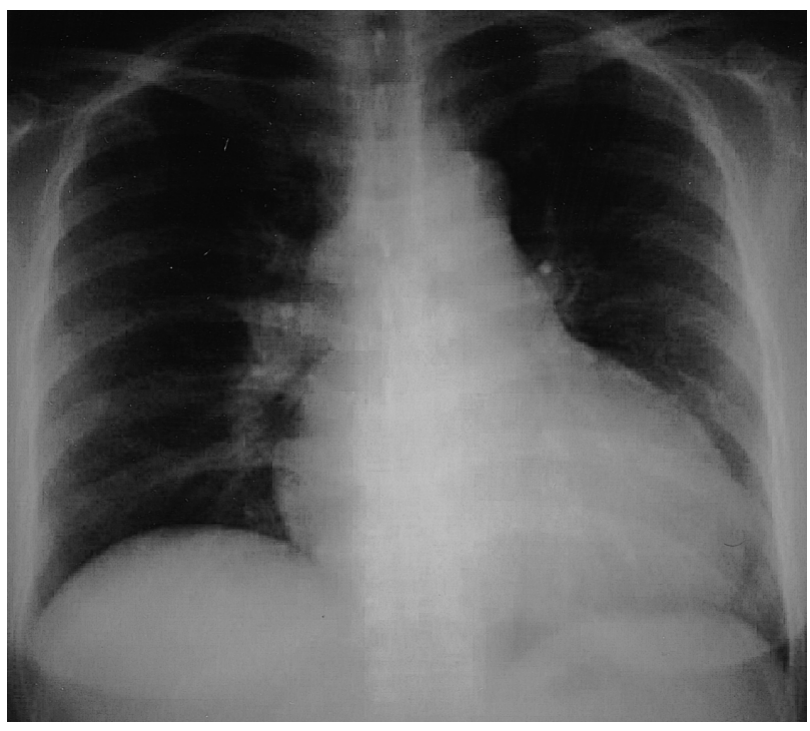

Fig 2. Chest radiograph on admission. Cardiomegaly (CTR 62\%) was seen.

(cardiothoracic ratio $(\mathrm{CTR})=62 \%)(\mathrm{Fig} 2)$. An echocardiographic study showed concentric left ventricular hypertrophy (the interventricular septum and the left ventricular posterior wall were both $1.5 \mathrm{~cm}$ thick), with no apparent wall motion disturbance (the ejection fraction of the left ventricle was 52\%). The E/A ratio was 0.68 (Fig 3). There was a small amount of pericardial effusion. The bone marrow aspiration revealed normal results, despite $0.1 \%$ atypical lymphocytes (Table 1).

Six days after admission, her blood pressure was 100/72 $\mathrm{mmHg}$, pulse rate was 120 beats/min, the third heart sound was audible and examination of the neck revealed an elevation of jugular venous pressure. Echocardiography revealed a moderate amount of pericardial effusion, the dimension of which was $0.9 \mathrm{~cm}$ in the end-diastolic phase. The thickness of the left ventricular wall was the same as in the previous study (Fig 3) and the left ventricular wall motion was almost normal (the ejection fraction of the left ventricle was 55\%). The color flow mapping did not show mitral or tricuspid regurgitation. The right heart catheterization showed a mean right atrial pressure of $13 \mathrm{mmHg}$, pulmonary capillary wedge pressure (PCWP) of $19 \mathrm{mmHg}$, cardiac index of $3.63 \mathrm{~L} \cdot \mathrm{min}^{-1} \cdot \mathrm{m}^{-2}$ and total systemic resistance index of 1497 dynes $\cdot \mathrm{sec} \cdot \mathrm{cm}^{-5} \cdot \mathrm{m}^{2}$. The elevated PCWP with subnormal ventricular systolic function suggested the existence of diastolic heart failure, and so treatment with diuretics and digitalis was started.

To elucidate the existence of specific myocardial disease, we performed a endomyocardial biopsy from the right ventricle on the 8th admission day. It revealed mild interstitial edema and mild nonspecific mononuclear cell infiltrates (Fig 4).

Blood pressure fell to $70 / 52 \mathrm{mmHg}$ on the 9 th admission day. Dopamin, dobutamin and noradrenalin were then started under the diagnosis of cardiogenic shock and decreased peripheral vascular resistance.

Abdominal computed tomography on the 9th admission day showed an abnormal mass of $9 \mathrm{~cm}$ in diameter at the upper side of the right kidney (Fig 5). Although catecholamines in the urine and blood were within the normal range, adrenal tumors, including pheochromocytoma, could not be ruled out at this time. The serum level of adrenomedullin was markedly elevated $(58.19 \mathrm{fmol} / \mathrm{ml})$ (Table 1). We therefore considered an open biopsy for further examination of the tumor, but repeated episodes of ventricular tachycardia and fibrillation prevented us from carrying out the procedure. On the 22nd day of admission, the patient died of progressive heart failure.

Postmortem findings were as follows. The heart weighed $560 \mathrm{~g}$. The epicardium was thickened and white in color, mimicking malignant mesothelioma. On the cut surface, the myocardium underwent necrosis with hemorrhagic 

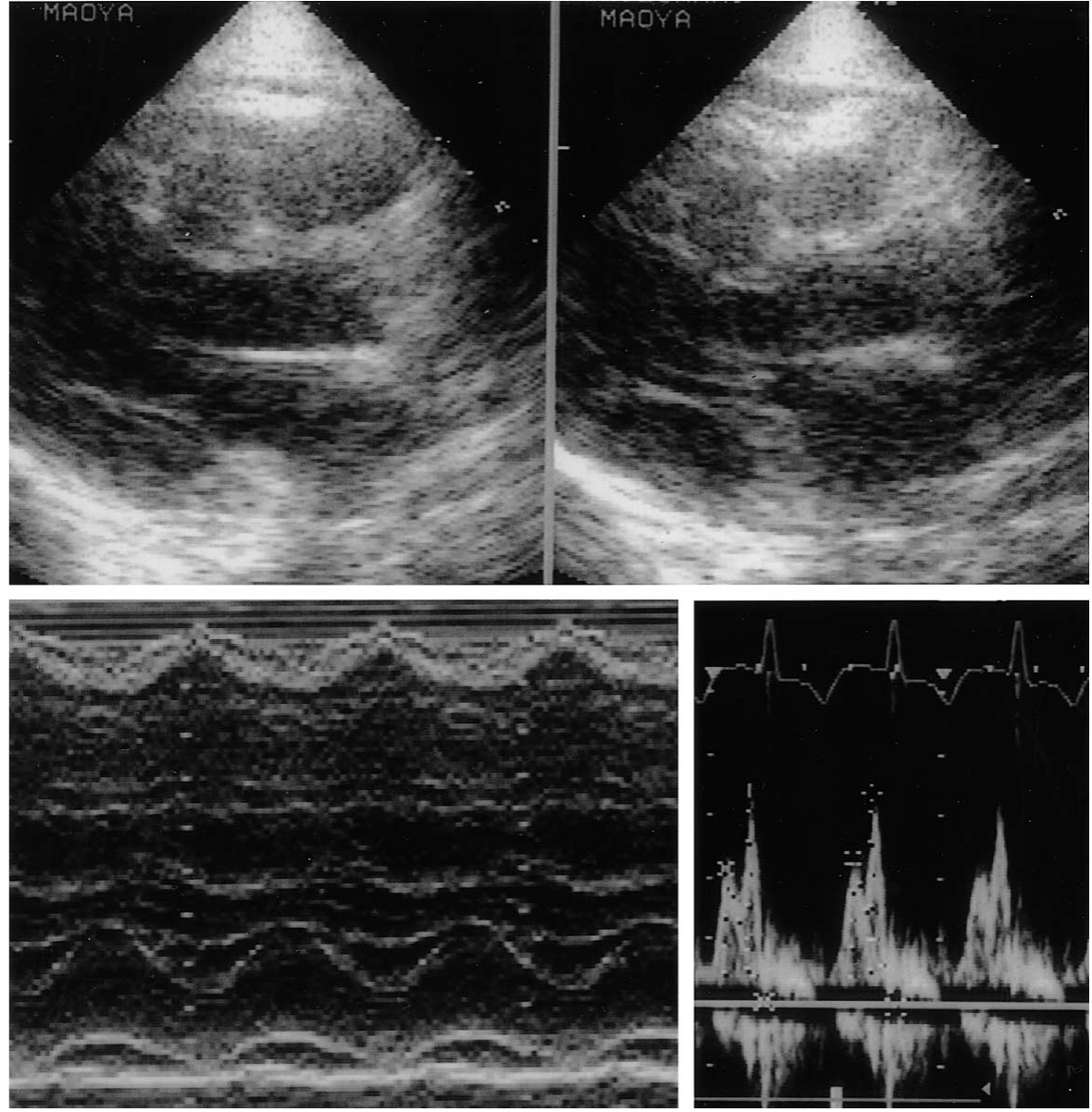

\section{A $\bar{B} \mid \mathbf{C}$}

Fig 3. Echocardiography on admission. Concentric left ventricular hypertrophy was noted with no apparent wall motion disturbance. There was a small amount of pericardial effusion (A, B). Left ventricular enddiastolic dimension, $4.9 \mathrm{~cm}$; left ventricular end-systolic dimension, $3.6 \mathrm{~cm}$; end-diastolic thickness of interventricular septum, $1.5 \mathrm{~cm}$; enddiastolic thickness of the left ventricular posterior wall, $1.5 \mathrm{~cm} ; \%$ fractional shortening, 27\%; ejection fraction, $52 \%$. The E/A ratio of the transmitral flow pattern was $0.68(\mathrm{C})$.

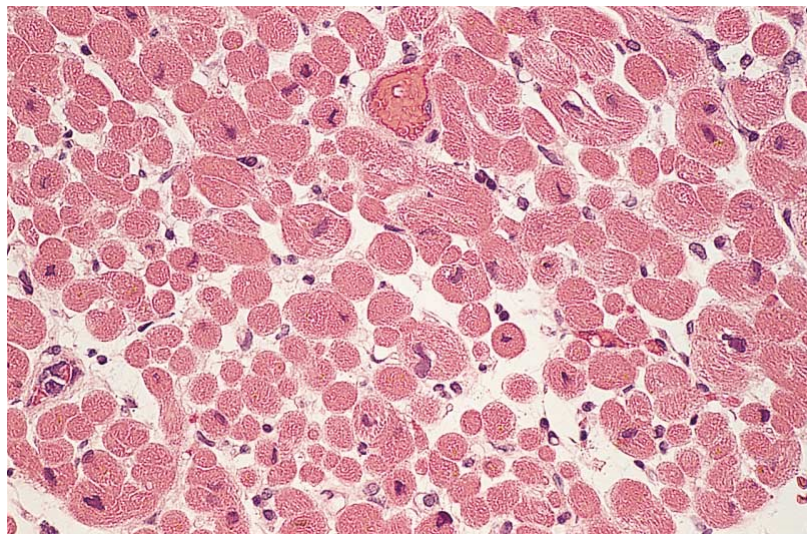

Fig 4. Endomyocardial biopsy on the 8th admission day. Mild interstitial edema and mild nonspecific mononuclear cell infiltrations were noted.

foci, and the tumor mass of the epicardium continuously invaded the myocardium, partly reaching the endocardium (Fig 6). On light microscopic examination, lymphoma cells had diffusely infiltrated the myocardium (Fig 7), but the degree of lymphoma cell infiltration was heterogeneous. The tumor mass, weighing $220 \mathrm{~g}$, above the right kidney was lymphoma tissue involving the right adrenal gland, which had mostly undergone necrosis. The left adrenal weighed $14 \mathrm{~g}$, twice the normal, and was also infiltrated with lymphoma cells. An immunohistological examination

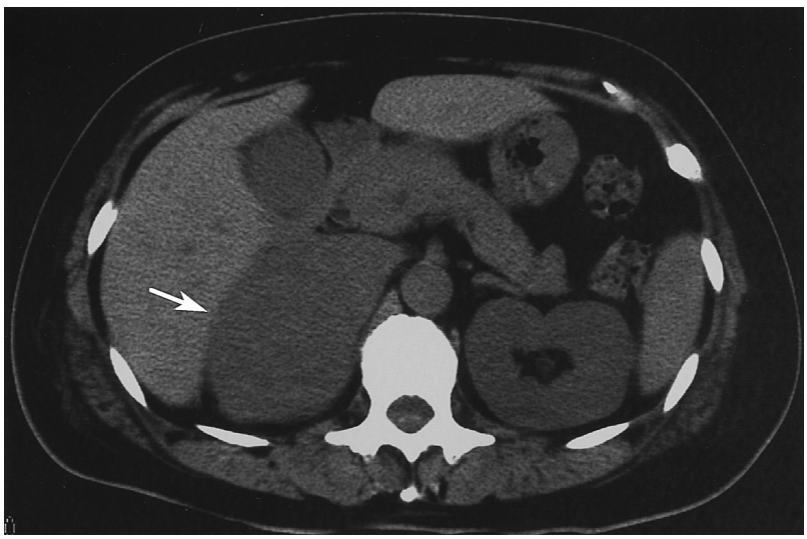

Fig 5. Abdominal computed tomography on the 9th admission day. A mass lesion of $9 \mathrm{~cm}$ in diameter was demonstrated at the upper side of the right kidney (arrow).

using lymphocyte markers demonstrated the lymphoma cells to be of T lymphocytic origin.

\section{Discussion}

\section{Diagnosis}

It has been reported that the echocardiogram is a useful tool for follow-up evaluation of cardiac involvements in patients who are already diagnosed with malignant lymphomas. ${ }^{4-6}$ But findings observed in this disease are often 

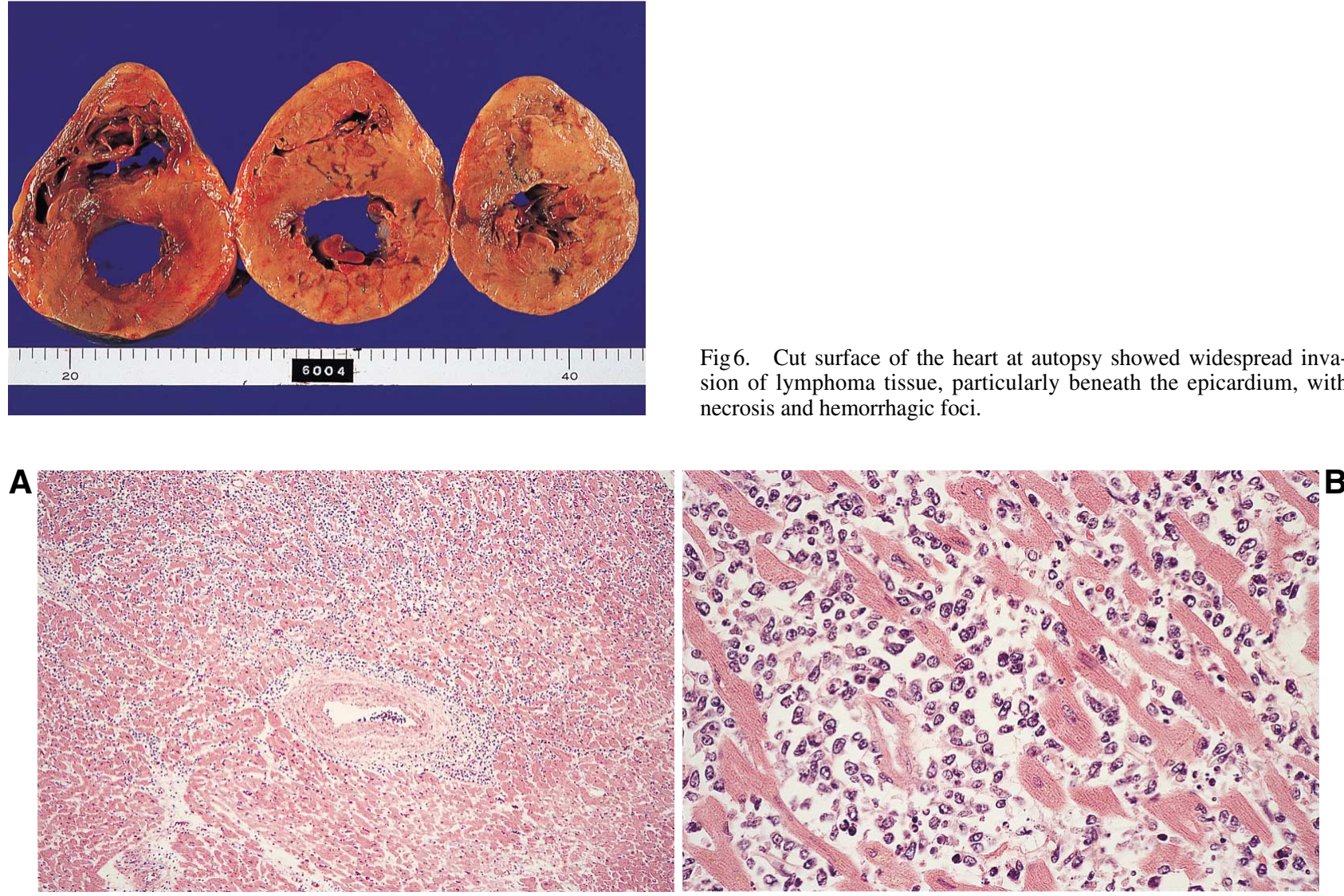

Fig 6. Cut surface of the heart at autopsy showed widespread invasion of lymphoma tissue, particularly beneath the epicardium, with necrosis and hemorrhagic foci.

Fig 7. Histological findings of the heart. Lymphoma cells had diffusely infiltrated the myocardium $(\mathrm{HE} ; \mathrm{A}: \times 16, \mathrm{~B}: \times 100)$.

nonspecific, mainly pericardial effusion and thickened ventricular wall. In the present case, definitive diagnosis of myocardial invasion with malignant lymphoma was difficult before death. Pericardial effusion and left ventricular hypertrophy were certainly observed; however, the histological findings of the endomyocardial biopsy were not significant, because the invasion of the tumor in the heart was predominantly in the epicardium and mid wall, which was clarified later at the autopsy.

\section{Cardiac Function}

Although cardiac symptoms rarely develop before death in patients with malignant lymphomas,-4 the first clinical symptoms in the present patient were dyspnea on exertion and general fatigue, which were thought to be symptoms of the heart failure. The right heart catheterization revealed that the cardiac index was normal and the PCWP was elevated. The echocardiogram showed preserved left ventricular systolic function and a decreased E/A ratio (0.68). These findings suggested that the heart failure in this case was mainly due to diastolic ventricular dysfunction. The elevated wall stiffness may have been due to the massive invasion of malignant cells.

We measured the serum adrenomedullin, because the existence of an adrenal tumor, including pheochromocytoma, had been suspected as associated with the unexplained hypotension. The serum adrenomedullin was markedly elevated in the present case, possibly resulting from destruction of the adrenals by lymphoma cell invasion. Elevations in adrenomedullin have been reported to decrease peripheral vascular resistance in some pathophys- iological conditions, such as heart failure or malignancy?-9 The elevation of adrenomedullin may have contributed to the relatively high output state in this case. Although the autopsy revealed that the malignant cells had infiltrated massively, the echocardiogram showed almost normal wall motion with a subnormal ejection fraction. The apparent causes of diastolic failure in this case were obscure; however, low systolic stress with a thick ventricular wall and reduced peripheral vascular resistance induced by adrenomedullin might be cofactors for the severe cardiogenic shock with subnormal ejection fraction.

\section{Acknowledgments}

The authors wish to express deep gratitude to $\mathrm{Dr} N$. Minamino at the Research Institute, National Cardiovascular Center for the measurement of adrenomedullin.

This study was supported in part by a Research Grant for Intractable Diseases from the Ministry of Health and Welfare of the Japanese Government, and a grant from the Vehicle Racing Commemorative Foundation of Japan.

\section{References}

1. Javier BV, Yount WJ, Crosby DJ, Hall TC: Cardiac metastasis in lymphoma and leukemia. Dis Chest 1967; 52: 481-484

2. Malaret GE, Aliaga P: Metastatic disease to the heart. Cancer 1968; 22: $457-466$

3. Roberts WC, Glancy DL, Devita VT: Heart in malignant lymphoma (Hodgkin's Disease, lymphosarcoma, reticulum cell sarcoma and mycosis fungoides). Am J Cardiol 1968; 22: 85-107

4. McDonnell PJ, Mann RB, Bulkley BH: Involvement of the heart by malignant lymphoma: a clinicopathologic study. Cancer 1982; 49: 944-951

5. Nagamine K, Noda H: Two cases of primary cardiac lymphoma 
presenting with pericardial effusion and cardiac tamponade. Jpn Circ J 1990; 54: $1158-1164$

6. Miyazaki Y, Yoshida T, Mori H, Yamazaki K, Handa S, Nakamura Y: Intractable heart failure, conduction disturbances and myocardial infarction by massive myocardial invasive of malignant lymphoma. $J$ Am Coll Cardiol 1985; 6: 937-941

7. Nishikimi T, Saito Y, Kitamura K, Ishimitsu T, Eto T, Kangawa K,et al: Increased plasma levels of adrenomedullin in patients with heart failure. J Am Coll Cardiol 1995; 26: 1424-1431

8. Kobayashi K, Kitamura K, Etoh T, Nagatomo Y, Takenaga M, Ishikawa $\mathrm{T}$, et al: Increased plasma adrenomedullin levels in chronic congestive heart failure. Am Heart J 1996; 131: 994-998

9. Miller MJ, Martinez A, Unsworth EJ, Thiele CJ, Moody TW, Elsasser T, et al: Adrenomedullin expression in human tumor cell lines. J Biol Chem 1996; 271: 23345-23351 